\title{
SYNTHETIC ROUTES AND NATURAL SOURCES OF 2-PYRIDONE DERIVATIVES AND THEIR PHARMACOLOGICAL ACTIVITY
}

\author{
PREM SHANKAR MISHRA ${ }^{1 a}$, RAVICHANDIRAN V ${ }^{2}$, VIJEY AANANDHI M $^{1 *}$
}

${ }^{1}$ Research Scholar Department of Pharmaceutical Chemistry and Analysis, Vels University, Chennai - 600 117, Tamil Nadu, India. ${ }^{2}$ Department of Pharmaceutical Chemistry, National Institute of Pharmaceutical Education and Research, Kolkata, West Bengal, India. Email: hodpchemistry@velsuniv.ac.in

Received: 18 February 2017, Revised and Accepted: 13 April 2014

ABSTRACT

Objective: 2-pyridone is a well-known heterocyclic ring having significant biological and medical application. The molecular structures and various activities of 2-pyridone derivatives as well as their syntheses and natural occurrence are analyzed and reviewed, and their reactivity toward various nucleophiles is discussed.

Methods: 2-pyridone derivatives, first naturally obtained and described as early as before the $19^{\text {th }}$ century, have been attracting increasing attention in view of their high reactivity as building blocks for the preparation of compounds of various classes due to their selective transformations with different reagents. Much information describing the natural occurrence, synthesis and the significant biological activity of 2-pyridone compounds are scattered throughout the literature. There are short chapters dealing with the synthesis and activity of 2-pyridone derivatives.

Results: After compiling the above material, the abundance of certain heterocyclic ring and nature of typical chemical transformations applied in current drug synthesis. It is likely this results from the abundance of these heterocycles in natural products such as alkaloids and various synthetic derivatives revealing different biological activity. This might suggest a classical approach to drug design where substrate analogs gain inspiration from existing natural ligands.

Conclusions: The data considered in this review clearly demonstrate the high synthetic potential of 2-pyridone derivatives. Many biologically active heterocyclic compounds have been obtained based on this heterocyclic ring. This suggests that 2-pyridone can be used in the design of novel highly effective pharmaceuticals with a broad spectrum of bioresponses.

Keywords: Naturally obtained 2-pyridone derivatives, Synthetic approach, Anticancer activity.

(c) 2017 The Authors. Published by Innovare Academic Sciences Pvt Ltd. This is an open access article under the CC BY license (http://creativecommons. org/licenses/by/4. 0/) DOI: http://dx.doi.org/10.22159/ajpcr.2017.v10i7.17989

\section{INTRODUCTION}

2-pyridone is an organic compound with the formula $\mathrm{C}_{5} \mathrm{H}_{4} \mathrm{NH}(\mathrm{O})$. This colorless crystalline solid is used in peptide synthesis. It is well known to form hydrogen-bonded structures somewhat related to the base pairing mechanism found in RNA and DNA. It is also a classic case of a molecule that exists as tautomers [1].

2-pyridone catalyzes a variety of proton-dependent reactions. 2-pyridone and some derivatives serve as ligands in coordination chemistry, usually as a 1,3 bridging ligand akin to carboxylate. A derivative has been isolated as a cofactor in certain hydrogenases [2]. The pyridine is found to have a large nunmber of biological activities those including antiviral, anticancer, antimicrobial, antidiabetic, and antitubercular [3]. In recent decades, a large number of pharmacological studies has been done on pyrimidine and their derivative. However, still more research is required to necessity the biological compounds. The pyrimidine derivatives show various biological activities including antitubercular, antioxidant, anti-inflammatory, anticonvulsant, antimicrobial, antibacterial, antiplasmodial, antifungal, anticancer, and analgesic activity [4].

\section{NATURAL PRODUCTS CONTAINING 2-PYRIDONE}

4-hydroxy-2-pyridone alkaloids exert diverse biological effects, ranging from antifungal, antibacterial, insecticidal and cytotoxic activity to the induction of neurite outgrowth in different cell assays [5]. For this reason, this class of compounds has attracted much attention in the scientific community, resulting in the elucidation of the biosynthesis of some members which are formed by fungal polyketide synthases through tetramic acids by fungal polyketide synthases as well as different total synthesis approaches [6].

2-pyridones are important compounds that are found in many active natural products and pharmaceuticals (Fig. 1) [7]. The history of the pyridone alkaloids dates back to the $19^{\text {th }}$ century, when Tuson isolated from castor beans a poisonous crystalline substance which he called ricinine [8]. The structural elucidation was accomplished in 1904 proposed the 2-pyridone core structure [9]. Many decades later, after preliminary data for two yellow pigments isolated from the insect pathogenic fungi Beauveria bassiana and Beauveria tenella in 1968 had been published, the structural features of the two fungal biochromestenellin and bassianin were unravelled in 1974 [10]. In the meantime, more pyridone alkaloids were isolated, e.g., flavipucine (1968), funiculosin (1969), ilicicolin $\mathrm{H}$ (1971), and the antibiotic kirromycin as a representative of the elfamycins. These findings enriched the field of pyridone alkaloids in natural product chemistry, which was opened in 1864 and still continues today, as fascinating structures are still being discovered [11]. These pyridonebased molecules have shown a broad range of biological properties such as antifungal, anti-HIV, antitumoral, anti-hepatitis B, MEK-1 inhibitors, receptor tyrosine kinase c-Kit inhibitors, anaplastic lymphoma kinase inhibitors, antimycobacterium tuberculosis agents, human rhinovirus $3 \mathrm{C}$ proteases, and anti Pim-1 kinase activities [12].

The 4-hydroxy-2-pyridone heteroaromatic core is increasingly attracting the attention ofscientific community due to its abundance of their in natural 2-pyridones alkaloid family and its implication in important biological systems [13]. Its biological action is mainly depended on the molecular decoration presented at 3 and 5-positions of its core (Fig. 2). Specific 3- 
<smiles></smiles><smiles>[R]c1cc(-c2c[nH]c(=O)c(C(=O)/C=C/C(C)=C/C(CC)CO)c2O)ccc1O</smiles>

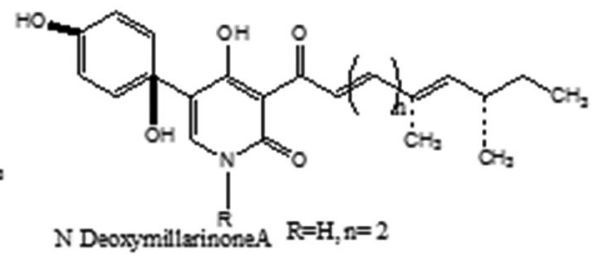<smiles>CCC(C)C=C(C)CC(C)(C)C(=O)c1c(O)c(C2=CCC(O)C=C2)cn(C)c1=O</smiles>

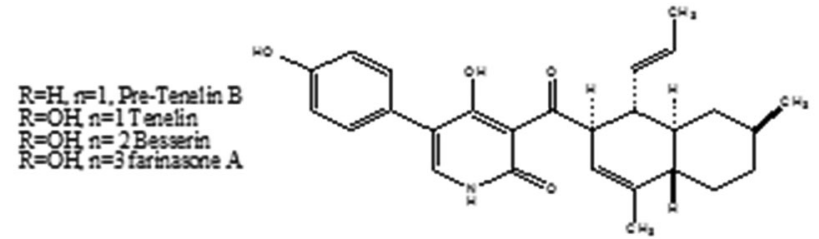<smiles>C=C1C(=O)C(C)=C(C)C(C)=C1C</smiles><smiles>C/C(C=CC(=O)c1c(Cl)c(-c2ccc(Br)cc2)c[nH]c1=O)=C\C(C)C</smiles>

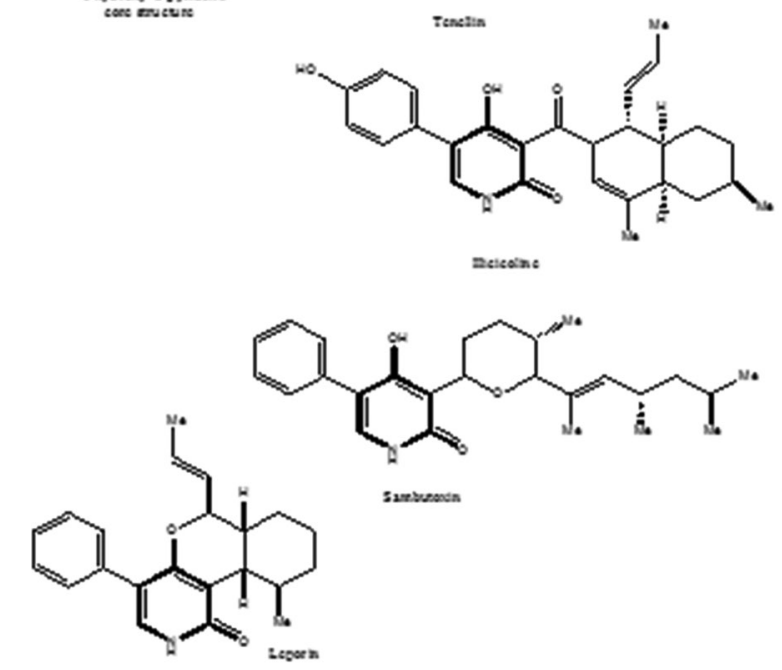<smiles>CC(CC(C)C(=O)c1c(O)nc(C#N)c(Br)c1Cl)C(=O)O</smiles>

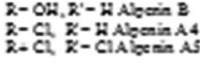

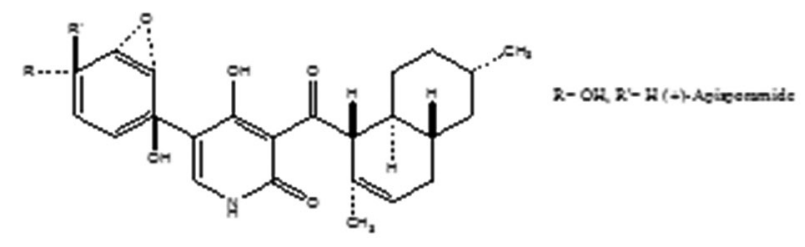

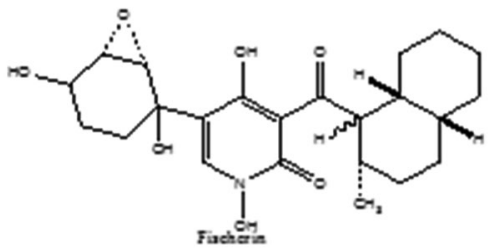

Fig. 1: Few naturally occurring 2-pyridones

other hand, selected 3-alkyl derivatives were documented as potent antibacterials and antimalarials, potentially through their ability to 
chelate iron [15]. Furthermore, bicyclic analogs of 2-pyridones, utilizing the 4-hydroxy-substituent in cycloetheric rings were also found to possess potent antibacterial activities [16]. Interestingly, aromatic bicyclic pyridones and especially furo[3,2-c]-pyridones-2 and their 2- and 4-thioderivatives were utilized as unnatural base pairs for the in vivo expansion of an organism's genetic alphabet and the prophylaxis or the treatment of obesity [17]. In Fig. 3, some important 4-hydroxy-2-pyridone have been listed which have shown potent bioactivity against cancer [18].

Although pyridone-2 derivatives are increasingly filling the biological active space, still their true biological profile is hampered by the unavailability of simple protocols for their synthesis. The past 5 years, tremendous efforts have been witnessed in utilizing direct functionalization practices to enrich the synthetic libraries of 2-pyridones and simplify synthetic protocols [19]. Following these efforts, pyridone-2 core and heteroaromatic analogs have been able to be functionalized selectively in 5- and 3-positions by utilizing mainly electrophilic palladation or radical initiated SOMO/HOMO interaction and in the 6-position by nucleophilic metal addition [20]. On the other hand, the literature is particularly poor when describing the direct functionalization of 4-hydroxy-2-pyridones. To the best of our knowledge, only couple of references exist describing their direct 3-alkylation, 3-arylation and very recently their 3-alkenylation with a limited number of activated styrenes byutilizing modified palladiumcatalyzed Tzuji-Trost, Suzuki and Heck-type reactions, respectively [21]. Surprisingly, none of the reports have described the direct access of asymmetric alkylation in 4-hydroxy-2-pyridone core structure and their application in drug development for cancer treatment [22]

a. Synthesis of citridone core structure by multi-step Tzuji-Trost reaction (L. Zografos et al.):

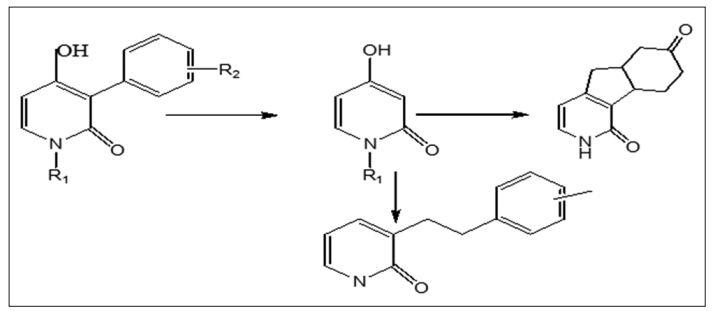

b. Synthesis of citridone core structure by metal catalyzed direct C-H functionalization (L. Zografos et al.):

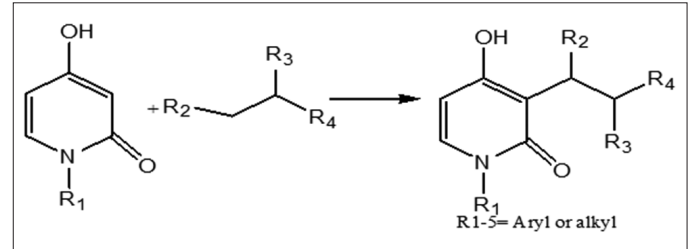

c. Total synthesis of citridone (L. Zografos et al.):

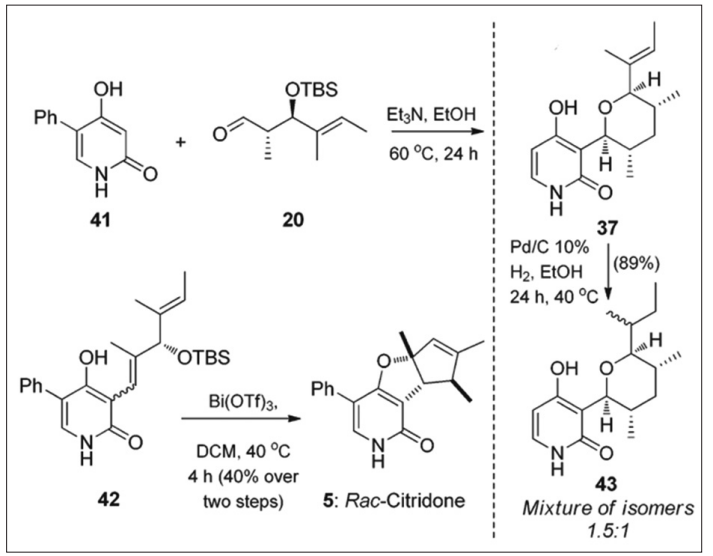

d. Semi synthesis of YCM1008A core structure (L. Zografos et al.):

\section{DEFINITION OF THE PROBLEM}

4-hydroxy-2-pyridone alkaloids constitute a family of natural products that is extremely wealthy in diverse biological activity and pharmaceutical applications mainly in cancer therapy [23]. Despite the increasing knowledge provided by the large number of isolated compounds of their family, numerous unanswered questions remain concerning their biosynthesis, unknown congeners, and most importantly their biological targets. Seeking to uncover missing biosynthetic links between apparently unrelated natural compounds, our interest focused on (1) development of novel synthetic strategy to introduce chiral center at 3-position of 4-hydroxy-2-pyridones (Fig. 4a) (2) development of novel synthetic strategy to construct furo[3,2-c]pyridin-4(5H)-one derivatives (Fig. 4b) and (3) study their potential activity to treat breast cancer [24].

\section{STRUCTURES, NATURAL SOURCES, AND KNOWN BIOACTIVITIES}

Due to the diversity of the pyridone natural products, they will be discussed with respect to the linkage in the 3-position, i.e., 3-acyl- 3-ether- and 3-alkyl-modified 2-pyridones. The following

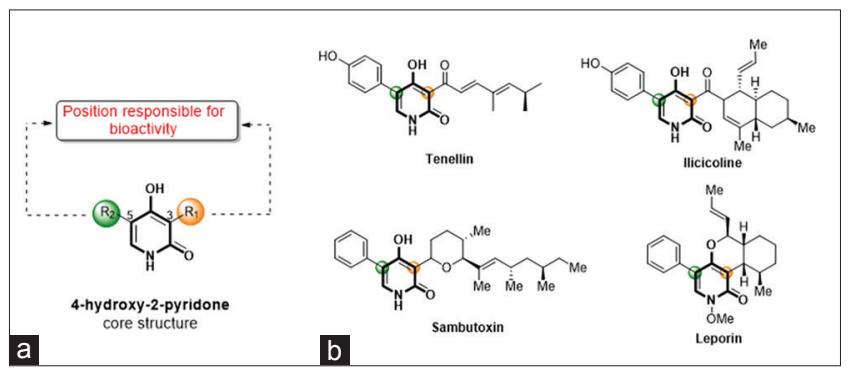

Fig. 2: (a) Potential bioactive position (3- and 5-) of 4-hydroxy2-pyridone core structure. (b) Important naturally occurring 2-pyridone alkaloid family having 3- and 5-substituted 4-hydroxy2-pyridone core structures

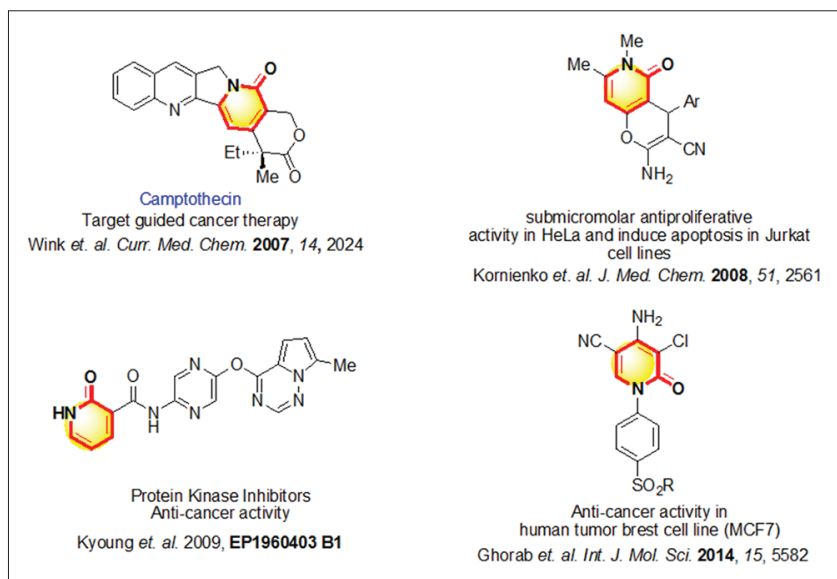

Fig. 3: Some important 2-pyridone derivatives have shown excellent activity against cancer cells

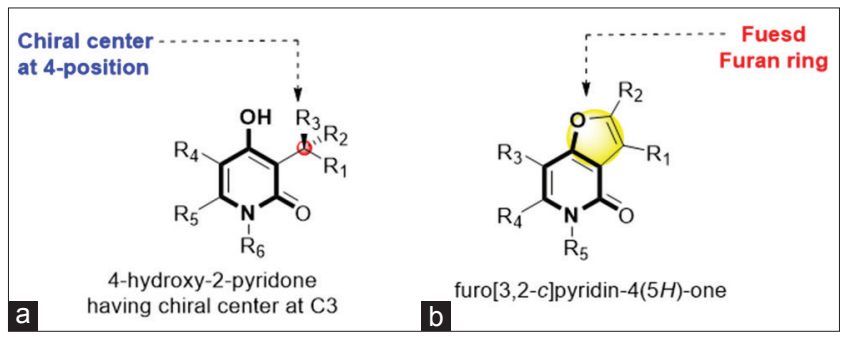

Fig. 4: Some 2-pyridone derivatives have shown chiral carbon center 
schemes will summarize the known structures. Although the elfamycintype pyridones also contain a 3-acyl modification, these compounds have been grouped separately for reasons of clarity [25].

The first group contains all 4-hydroxy-3-acyl-modified 2-pyr-idones and ricinine (1) (Scheme 1). Ricinine (1) is an insecticidal and hepatotoxic alkaloid produced by Ricinus communis which is present in high concentrations in the whole plant (ca. $1 \mathrm{mg} / \mathrm{g}$ fresh weight) [26]. The cytotoxic aspyridones A and B were discovered in the filamentous fungus Aspergillus nidulans as the product of a silent PKS-NRPS cryptic gene cluster. This gene cluster was activated by ectopic expression under control of an inducible promoter. With this technique, the best producer strain generated 2 and 3 from 0.5 to $1 \mathrm{mg} / \mathrm{L}$ of culture broth, enough to determine the relative configuration [27]. This discovery bears the implication that different pyridone alkaloids may still be found hidden in silenced gene clusters in many other species. Aspyridone B (3) is the only known pyridone alkaloid containing a catechol moiety, whereas the p-hydroxyphenyl moiety is found in many other pyridone alkaloids. Pyridovericin is one of the many examples featuring this substitution pattern. Originally isolated from the entomopathogenic fungus B. bassiana in 1998, it was found to inhibit protein tyrosine kinase at high concentrations $(100 \mathrm{mg} / \mathrm{mL})$ in crude cell homogenates from NIH3T3/v-src1.12. Its absolute configuration was determined by a very interesting quasi-racemic synthesis in 2002, 13 [2]. A group of similar pyridone alkaloids are the yellow biochromestenellin and its congeners pre-tenellin, bassianin and farinosone A and B. Tenellin was first isolated from the entomopathogenic fungus B. tenella in 1968 and later also found in B. bassiana [28]. Along with bassianin, it was found to be an inhibitor of ATPase in isolated membranes. Studies to unravel the biosynthesis of tenellin have been performed, which are beyond the scope of this article. In general, however oxidative ring expansion of tetramic acids to 2-pyridones is thought to be the process involved. Two racemic syntheses of tenellin were developed in 1982 and 1989, but the absolute configuration still remains unknown [29]. Pre-tenellin B was isolated after knockout of one of the two open reading frames encoding for a cyp450 oxidase using RNA silencing techniques. Therefore, pretenellin B was found to be the direct precursor of tenellin [30]. More recently, the tetraene 2-pyridones farinosone $\mathrm{A}$ and $\mathrm{B}$ along with the biosynthetically related farinosone $\mathrm{C}$ have been isolated from the entomopathogenic fungus Paecilomyces farinosus by bioassay-guided fractionation [31]. Farinosone A-induced neurite outgrowth in the PC-12 assay, whereas farinosone B was inactive. The absolute configuration of these natural products remains unknown. Other closely related natural products are the militarinones [6,7], isolated from the mycelium of the entomogenous fungus Paecilomyces militaris (or P.farinosus) in the years 2002-2006. These natural products induced neurite outgrowth in the PC-12 assay at low concentrations by persistently activating the PI3-K/ $\mathrm{PKB}$ and the MEK/ERK pathways. Militarinone A was also capable of inducing apoptosis in the murine neuroblastoma cell line N2a by nuclear translocation of the apoptosis-inducing factor [32]. Deoxymilitarinone A was cytotoxic in human neuronal IMR-32 cells at concentrations of $100 \mathrm{mM}$. It is interesting to note that its hydroxamic acid was isolated from two different strains differed in their signs of optical rotation, although homochirality of these compounds may not generally be assumed. The relative configuration, however, has been tentatively assigned as syn. Pyridomacrolidin is the only known pyridone alkaloid containing a 10-membered cyclic lactone. It was isolated in 1998 from B. bassiana along with pyridovericin and found to be a weak inhibitor of protein tyrosine kinase. The absolute configuration is unknown, and there is only one recent study toward a biomimetic synthesis [33]. The antifungal antibiotic ilicicolin $\mathrm{H}$ was isolated in 1971 from the mycelium of the imperfect fungus Cylindrocladium ilicicola. Its absolute configuration and biosynthesis have been investigated [34]. In addition, in 1985 a racemic total synthesis using an intra-molecular Diels-Alder strategy was presented [35]. Harzianopyridone was isolated in 1989 from the fungus Trichoderma harzianum as a racemic mixture and reported to be an antifungal agent. Later on, a levorotatory sample was also found to be inhibitory toward etiolated wheat coleoptiles (herbicidal) and an inhibitor of the mitochondrial complex II [36].

In 1988, the three antifungal antibiotics atpenin B, A4 and A5 were isolated from Penicillium sp. followed by the total structural elucidation in 1990 of atpenin A 4 by X-ray crystallography [36,37]. Like harzianopyridone, the atpenins were found to be mitochondrial complex II inhibitors. Atpenin B was obtained in racemic form from a total synthesis in 1994, whereas atpenin A5 was stereoselectively synthesized in 2009 [38].

The second group comprises the 4-oxy-3-alkoxy-2-pyridones shown in Scheme 1. TMC-69 is an antitumor antibiotic from Chrysosporium sp. that induced prolongation of the survival time of mice transplanted with B16 melanoma and P388 leukemia. The absolute configuration of the THP-moiety could be determined by degradation studies, while the stereogenic center of the side chain remains unassigned and transformed it into its stable hexahydrogenated form TMC-69-6 [39]. Hand reported that this molecule was a selective inhibitor of the

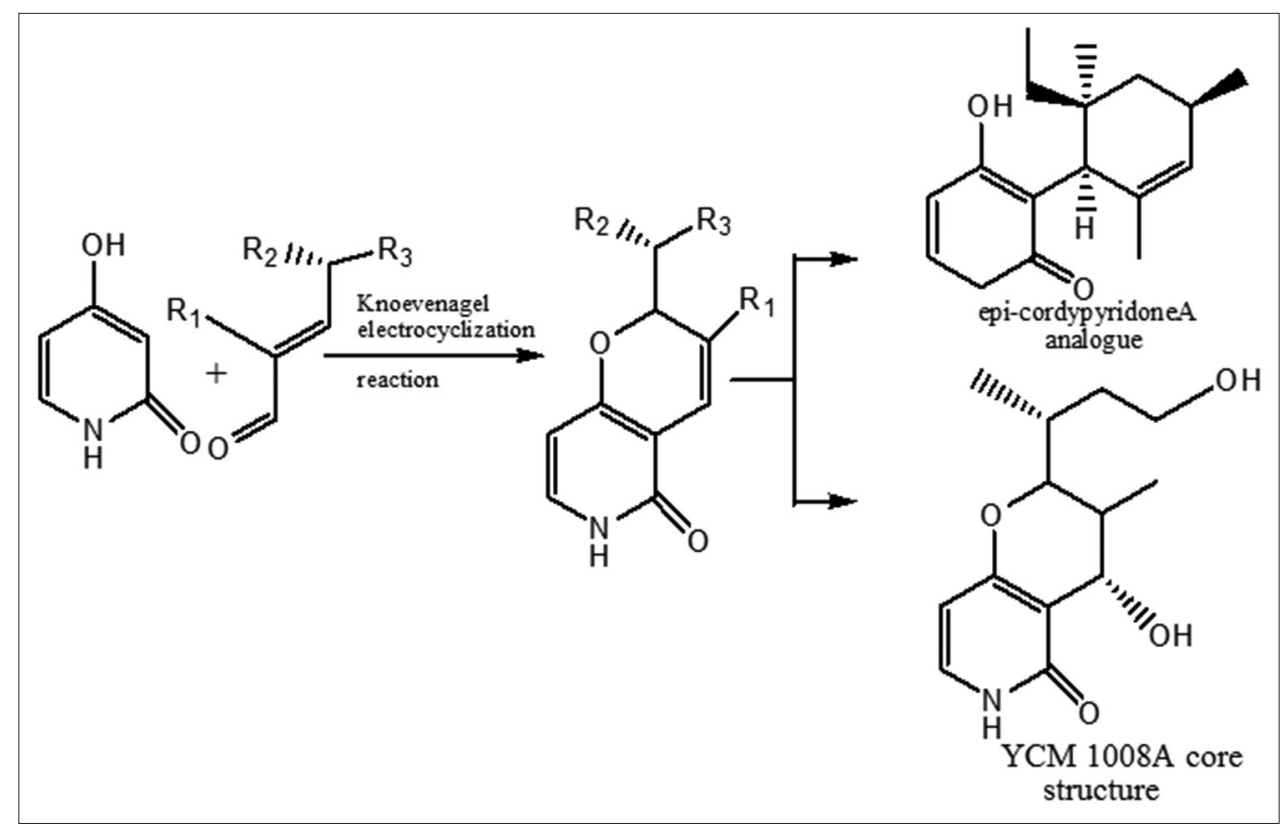

Scheme 1: Known synthetic strategy to construct highly biologically potent 3,5-substituted 4-hydroxy-2-pyridones 
dual specificity phosphatases Cdc25 A and B. It was found a different phosphatase inhibition profile with low inhibition of Cdc25A but high inhibition of other phosphatases, e.g., PTP1B and VHR [39]. Fusapyridon A and its dimethyl ketalfusapyridon B were isolated in 2007 from Fusarium sp. and fusapyridon A exhibited antimicrobial activity against Pseudomonas aeruginosa and Staphylococcus aureus [40]. Their structures resemble 4, 60-anhydro-oxysporidinone from an endophytic strain of Fusariumoxysporum, with fusapyridone A. The absolute stereostructure and parts of the relative configuration remain to be solved. 4, 60-anhydro-oxysporidinone has so far not been found to exert any biological activity in laboratory systems $[40,41]$.

Funiculosin with broad antifungal properties was discovered as early as 1969. Its absolute stereostructure was solved in 1978 by X-ray crystal structure analysis and hydrogenation experiments. It was the first natural product containing a unique all-syncyclo pentanetetrol moiety [42].

Tricyclic biarylleporins A and B were isolated from Aspergillus leporis in 1991 and 2003, respectively. Leporin A (33) shows activity against the corn earworm Helicoverpa zea and moderate antibacterial activity against Bacillus subtilis. The relative stereostructure of leporin A was solved and verified in a racemic total synthesis in 1996 [42,43]. Leporin $B$ is an inducer of the hexokinase II gene (HKII). It was identified with a rat myoblast cell construct expressing the reporter gene luciferase under control of the HKII promoter. Thus, enhancement of HKII transcription enhanced the luciferase signal $[43,44]$. The relative configuration was solved by X-ray diffraction. It was active in the Rev binding assay, rendering it a potential antiviral substance, and was also active against Candida albicans and Penicillium chrysogenum (MICs 16 and $8 \mathrm{mg} / \mathrm{mL}$, respectively). Its antitumor potency was found in vitro but not in vivo against Madison lung carcinoma cell line M109 (1 mg/mL). Epipyridone is the p-hydroxyphenyl modified derivative of fusaricide. Its natural source is the endofungal filamentous fungus Epicoccum sp. The authors suggest an interesting biosynthetic proposal for the side chain through an intramolecular hetero-Diels-Alder reaction, which would also be valid for the construction of the structures, e.g., fusaricide and PF1140. No bioactivity has yet been assigned for epipyridone, and only the relative configuration is known [45].

Hence, many researcher have focused on leukemia treatment. Primary treatments available for leukemia are radiotherapy, bone marrow transplant, biotherapy, surgery, and chemotherapy. BCR-ABL tyrosine kinase inhibitor, e.g., imatinib mesylate has revolutionized and set the landmark in this field [46]. PIM-1 (Proto-oncogenic encodes for serine/ threonine kinase) kinase have been shown to be overexpressed in a variety of cancer cell lines. 2-oxo-3-cyanopyridine derivative, 4,6-diaryl2-oxo-1,2- dihydropyridine-3-carbonitriles has shown inhibition of the oncogenic serine/threonine kinase PIM-1, which plays a role in cancer cell survival, differentiation and proliferation [47].

\section{Synthetic approach}

The 2-pyridone derivatives were synthesized by various scientists, by approaching deferent versatile route and exhibiting various activities.

Karam et al. 2014 reported as Src kinase, a prototype member of the Src family of kinases, is over-expressed in various human tumors and has become a target for anticancer drug design. In this perspective, a series of eighteen 2-pyridone derivatives were synthesized from corresponding. In the case of dihydroxyacetophenone, first, mono- $O$ acetylation was carried out using acetic anhydride and pyridine while o-hydroxyacetophenone was used as such. 4-0xo-4H-1-chromen3-yl-carbaldehydes were then synthesized using Vilsmeir-Haack formylation reaction and evaluated for their c-Src kinase inhibitory activity. Among them, eight compounds exhibited c-Src kinase inhibitory activity with IC50 value of less than $25 \mu \mathrm{M}$. Compound 1-[2-(dimethylamino) ethyl]-5(2-hydroxy-4-methoxy benzoyl) pyridin-2(1H)-one exhibited the highest c-Src kinase inhibition with an IC50 value of $12.5 \mu \mathrm{M}$ [48].

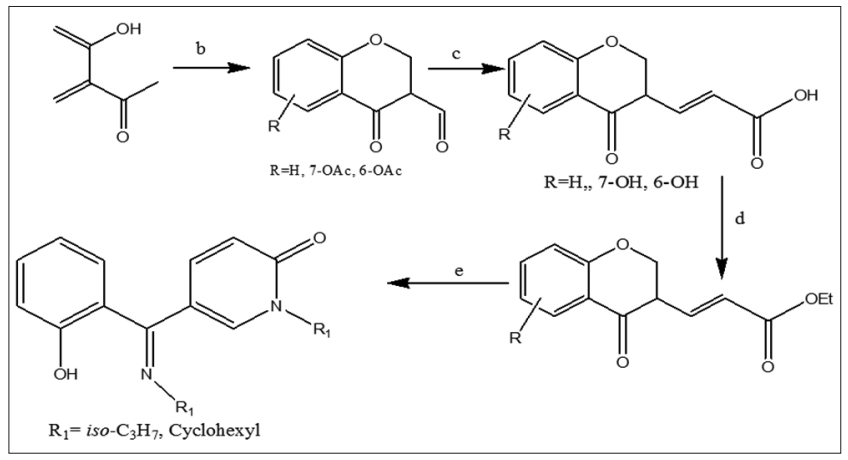

(b) POCl3, DMF, $50^{\circ} \mathrm{C}, 13 \mathrm{~h}$; (c) $\mathrm{CH} 2(\mathrm{COOH}) 2$, pyridine, $1.5 \mathrm{~h}$; (d) EtOH, conc. H2SO4 (3 or 4 drops), 12 h; (e) CH3I, K2CO3, anhyd.acetone, reflux, $12 \mathrm{~h}$.

Mijin et al. 2014 synthesized 2-pyridones as well as 2-pyridone-based compounds, such as 2-quinolones, using microwave assisted organic chemistry is reviewed. $N$-substituted 4,6-dimethyl-3-cyano-2-pyridones were obtained from acetylacetone and the corresponding $N$-substituted cyanoacetamide using conventional and microwave synthesis in the presence of piperidine as a catalyst gave a good yield [49].

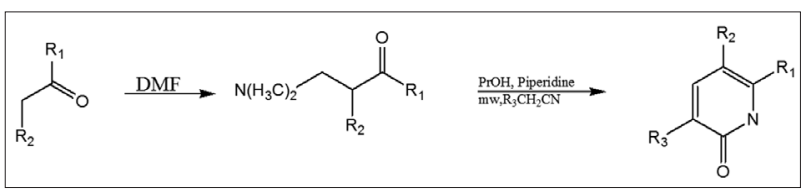

Where $\mathrm{R}_{1}=\mathrm{H}, \mathrm{CH}_{3} ; \mathrm{R}_{2}=\mathrm{H}, \mathrm{CH}_{3} ; \mathrm{R}_{3}=\mathrm{C}_{6} \mathrm{H}_{5}$

Seifi et al. 2013 Magnesium oxide and bismuth(III) nitrate pentahydrate as highly effective catalysts which have catalyzed the three-component reaction of cyanoacetic acid hydrazide, aldehydes, and malononitrile to prepare of the corresponding $\mathrm{N}$-amino-2-pyridones [50].

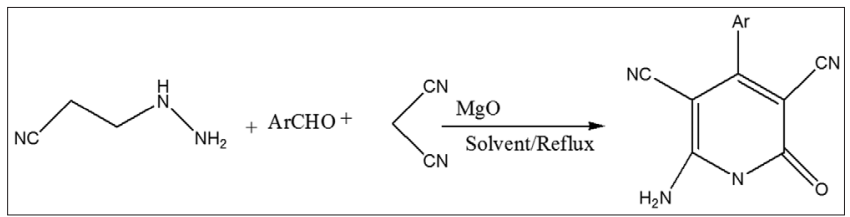

Mehrparvar et al. 2013 prepared a novel analog of 2-pyridone3 -carboxylic acids by the three-component reaction of 3 -formyl chromone, Meldrum's acid, and primary amines in the presence of a catalytic amount of diammonium hydrogen phosphate in water. Goodto-high yields, easy work-up, and an environment- tally friendly profile are the advantages of this method for the synthesis of 2-pyridone-3carboxylic acid derivatives [51]

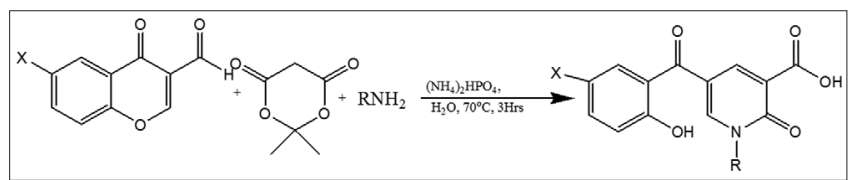

\section{$\mathrm{R}=\mathrm{H}, \mathrm{Cl}, \mathrm{Br}$}

Al-Abdullah 2011 prepared the title compounds by reaction of 6-acetyltetralin with different aromatic aldehydes, namely, 2,6dichlorobenz-aldehyde, 2,6-diflourobenzaldehyde, and 3-ethoxy4-hydroxybenzaldehyde, to yield the corresponding $\alpha, \beta$-unsaturated ketones $3 a-c$. Compound $3 b$ was reacted with hydrazine hydrate to yield the corresponding 2-pyrazoline 4 , while compounds $3 \mathrm{a}$,b reacted with thiourea to afford the 2 -thioxopyrimidine derivatives $5 \mathrm{a}, \mathrm{b}$, respectively. The reaction of 1 , and the aromatic aldehydes $2 \mathrm{a}-\mathrm{c}$ with ethyl 
cyanoacetate, 2-cyano-thioacetamide or malononitrile in the presence of ammonium acetate yielded the corresponding 2-oxopyridines $6 \mathrm{a}, \mathrm{b}, 2$-thioxopyridines or 2-iminopyridines, respectively. The newly prepared compounds were evaluated for anticancer activity against two human tumor cell lines. Compound 3a showed the highest potency with IC50 $=3.5$ and $4.5 \mu \mathrm{g} / \mathrm{mL}$ against a cervix carcinoma cell line (Hela) and breast carcinoma cell line (MCF7), respectively [52].

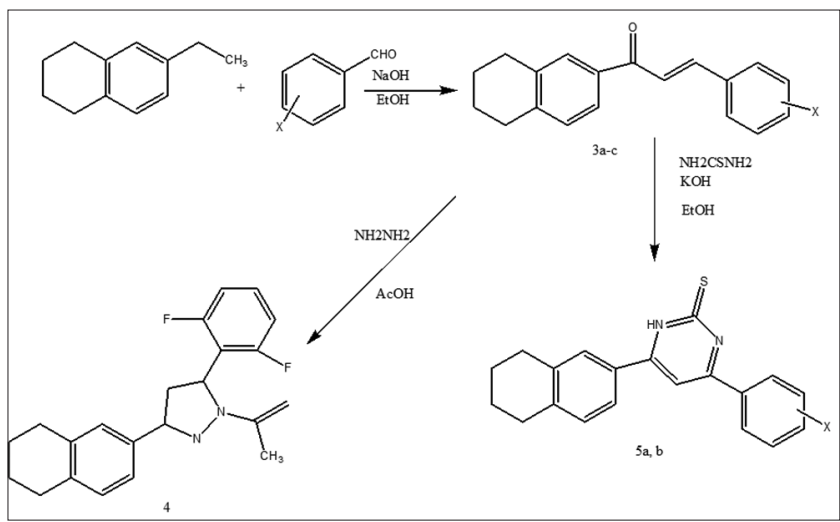

Lv et al. 2010 synthesized a series of novel 2-pyridone derivatives and evaluated for their antihepatitis B virus (HBV) activity and cytotoxicity in vitro. Moderate to good activity against HBV DNA replication was observed in these 2-pyridone analogs. The most active compounds were $5 \mathrm{~d}$ and 6l, with good inhibitory activity against HBV DNA replication (IC50 $=0.206$ and $0.12 \mu \mathrm{M}$, respectively) and remarkable high selectivity (selectivity indexes of $>532$ and 467 , respectively). A pharmacophore model of the synthesized compounds was proposed by the GASP program. The pharmacophore model consists of three hydrophobic points, four HBA points, and one HBD point. The 2-pyridone derivatives represent a novel class of HBV inhibitors, which are worth further optimization [53].

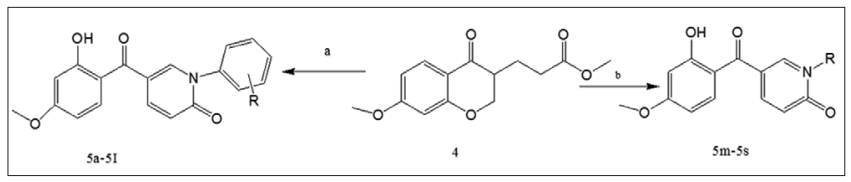

$\mathrm{R}=\mathrm{H}, 4-\mathrm{OCH}_{3}, 2-\mathrm{OCH}_{3}, 4-\mathrm{OCH}_{2} \mathrm{CH}_{3}$

Tkachova et al. 2010 reported a sodium ethoxide catalyzed reaction of $\mathrm{N}$-substituted cyanoacetanilides with diethyl 2-(ethoxymethylene) malonate unexpectedly leads to the corresponding 2-amino-5-cyano6-oxo- $N, 1$-diaryl-1,6-dihydropyridine-3-carboxamides, while the expected 5-cyano-2-hydroxy-6-oxo-1-aryl-1,6-dihydropyridine-3carboxylates were observed only as minor products [54].

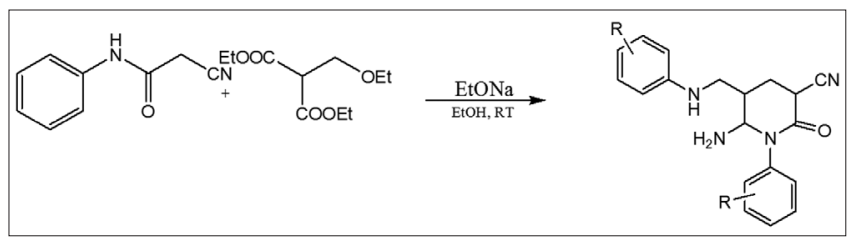

Jacinto et al. 2009 reported a commercial dehydroacetic acid was converted into 4-hydroxy-6-methylpyridin-2(1H)-one (3), which was then condensed with several aliphatic aldehydes to produce seven new title compounds in variable yields (35-92\%). Reaction with $\alpha$, $\beta$-unsaturated aldehydes resulted in the formation of condensed pyran derivatives. A mechanism is proposed to explain the formation of such compounds. The effects of all methylpyridin-2(1H)-one derivatives on the development of the dicotyledonous species Ipomoea grandifolia and Cucumis sativus, and the monocotyledonous species Sorghum bicolor were evaluated. At the dose of $6.7 \times 10^{-8}$ mola.i./g substrate, the compounds showed some phytotoxic selectivity, being more active against the dicotyledonous species. These compounds can be used as lead structures for the development of more active phytotoxic products [55].

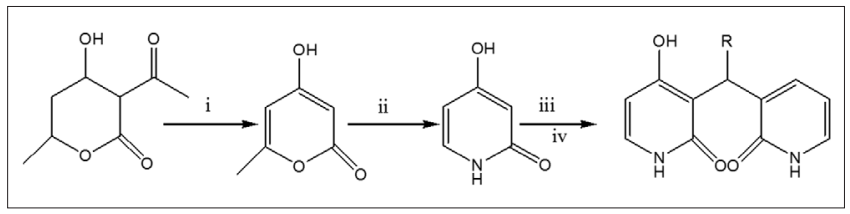

$\mathrm{i}=\mathrm{H} 2 \mathrm{SO} 4,130 \mathrm{oC}, 10 \mathrm{~min}$; (ii) $\mathrm{NH} 4 \mathrm{OH}, 100^{\circ} \mathrm{C}, 6 \mathrm{Hrs}$, (iii) ethanol/ methanol, piperidine, pyridine (iv) $\mathrm{RCHO}$; $\mathrm{R}=\mathrm{CHO}$

Tugusheva et al. 2006 reported new approaches to the synthesis of the previously unknown pyrimidine, 4-amino-2-pyridone, and 4-aminopyridine derivatives were developed based on the reactions of enamino amides with dimethylformamide dimethyl acetal. New structural modifications of 4-amino-2-pyridone derivatives were performed. Numerous compounds of this type, which are of interest for biological studies, were prepared [56].

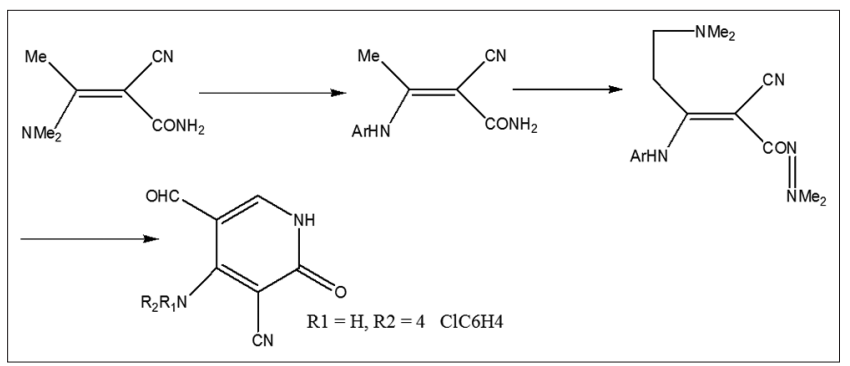

Yu et al. 2006 reported a catalytic oxidative coupling between acrylamides and alkynes was achieved using $0.5 \mathrm{~mol} \%$ loading of [RhCp* $\mathrm{Cl} 2] 2$ with $\mathrm{Cu}(\mathrm{OAc}) 2$ as an oxidant. 2-pyridones, iminoesters, and substituted indoles could be obtained as a result of the electronic and steric effects of the substituents in the acrylamides [57].

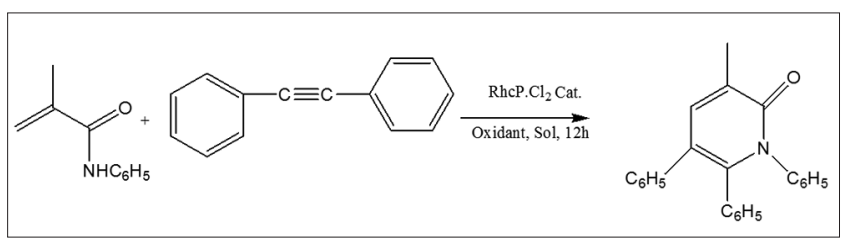

Ando et al. 2006 synthesized a novel one-pot synthesis of $\mathrm{N}$-difluoromethyl-2-pyridones is described. $\mathrm{N}$-(pyridin-2-yl) acetamide derivatives were excellent precursors for the preparation of N-difluoromethyl-2-pyridone derivatives. Difluoromethylation of 2-acetaminopyridine derivatives was achieved with sodium chlorodifluoroacetate as a difluorocarbene source in the presence of a catalytic amount of 18-crown-6. Subsequent in situ hydrolysis of resultant 1,2-dihydro-2-acetimino-1-difluoromethylpyridines proceeded under mild acidic conditions to afford the corresponding $\mathrm{N}$-difluoromethyl-2-pyridones in moderate to good yields [58].

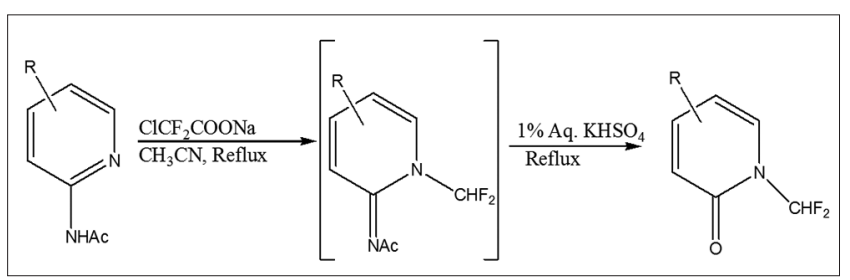

Kajal and Devakumar 2005 reported augmentation of wheat production calls for introduction of wheat hybrids in cultivation. In the absence of viable alternative technology of hybrid wheat development, chemical 
induction of male sterility mediated technology based on chemical hybridizing agents (CHAs) holds a great potential. The QSAR method was applied to two families of CHAs in the $\mathrm{N}$-acylanilines and pyridone class of chemistry.

The models for each CHA family gave good correlation between the variations in log percent of male sterility and the steric-electrostatic properties of the sets. QSAR analysis has revealed a direct relationship of the Swain-Lupton constant Fp and molecular mass but an inverse relationship of molar refractivity (MR), ES, and Swain-Lupton resonance constant $\mathrm{R}$ in influencing the bioactivity in the $\mathrm{N}$-acylanilines. QSAR analysis of four parent families consisting of two training sets each of pyrid-2-ones and prid- 4-ones revealed the positive contributions of field effect exemplified by the Swain-Lupton field constant (F) and the negative contributions of the MR of aromatic substituents in all but one training set. The QSAR models also indicated that increased steric bulk at the 4-position on the phenyl ring is associated with enhanced activity [59].

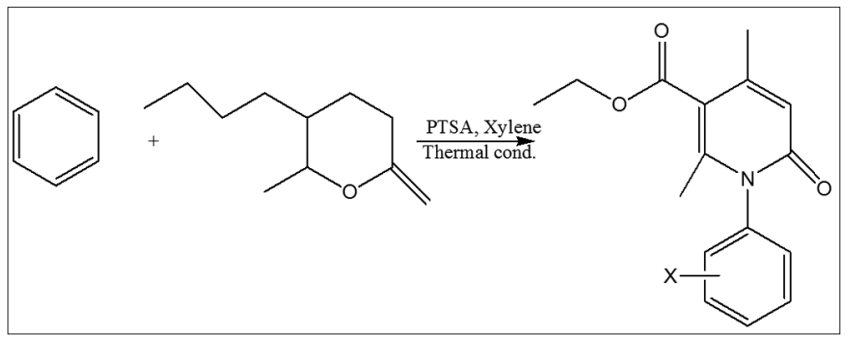

Desai et al. 2006 reported a series of benzimidazole bearing 2-pyridones $5 \mathrm{a}-\mathrm{k}$ were synthesized and assessed in vitro for their activity as antimicrobial agents using the conventional broth dilution method. The results of the antimicrobial study revealed that compounds exhibited substantial antibacterial activity and emerged as a more potent antifungal agent compared to the standard drugs chloramphenicol and ketoconazole, respectively. It was observed that the presence of inductively electron withdrawing groups remarkably enhances the antibacterial activity of the newly synthesized compounds. Cytotoxicity studies suggested that none of the tested compounds exhibited any significant cytotoxic effects [60].

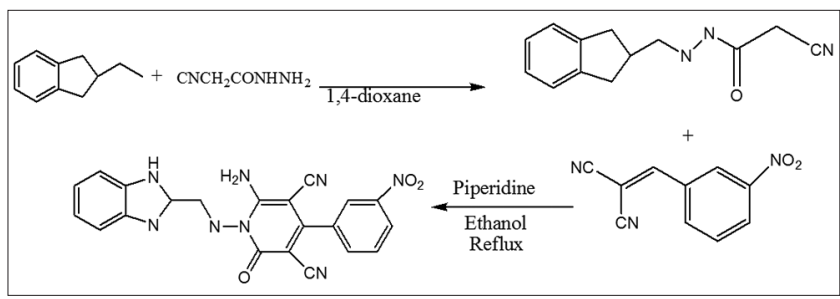

Fischer et al. 2004 synthesized series of 3-cyano-pyridones carrying a variety of alkyl substituents at C-5 and C-6 have been synthesized and their solid-state structures have been studied. Hydrogen bonding interactions between individual pyridone molecules lead either to the formation of symmetric dimers of the R22 (8) type or to helical chains of the C (4) type, which was based on the known and calculated structures for the 2-pyridone parent system [61].

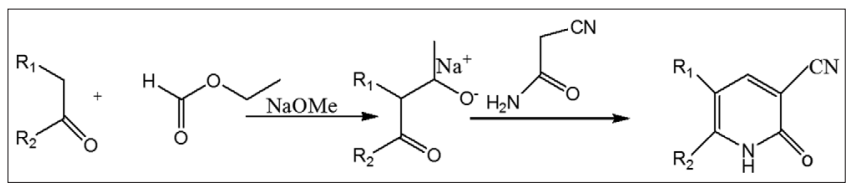

\section{CONCLUSIONS}

Pyridone alkaloids constitute a remarkable class of secondary metabolites. Due to their diversity, many different biological effects of these compounds have been identified, which may, however, not always be related to their original biological function. Their versatile and diverse structures resulting from different modifications in all positions of the pyridone core should render these compounds a fascinating playground for synthetic chemists for many decades. Despite the innovative synthetic approaches that have been developed to obtain these natural products, much work remains to be done, as many of the known structures have not been determined in full detail. Likewise, the synthesis of derivatives to generate structure-activity relationships has not found too much attention. The original biological functions of these secondary metabolites remain largely unknown despite speculations about the metal-sequestering properties of hydroxamic acids. Other biological aspects, e.g., the biosynthesis of tenellin, have been clarified in great detail. Other closely related structures such as (for example) the lycopodium alkaloids have been reviewed, 116 and there are many more related structures incorporating the 2-pyridone core. It is also noteworthy that the 2-pyridone structure can be found in approved drugs such as milrinone, 117, 118 making these compounds and the development of various versatile synthetic approaches a fusion of natural product as well as synthetic product in medicinal chemistry.

\section{ACKNOWLEDGMENT}

The authors are thankful to Vels University (VISTAS) and its management for providing research facilities and encouragement

\section{REFERENCES}

1. Ravinder M, Mahendar B, Mattapally S, Hamsini VK, Reddy V, Rohit C, et al. Eco-friendly synthesis of diverse and valuable 2-pyridones by catalyst- and solvent-free thermal multicomponent domino reaction. J Bioorg Med Chem Lett 2012;22:6010.

2. Jessen HJ, Gademann K. 4-hydroxy-2-pyridone alkaloids: Structures and synthetic approaches. Nat Prod Rep 2010;27(8):1168-85.

3. Chaube A, Pandeya SN. Pyridine a versatile nucleuse in pharmaceutical field. Asian J Pharm Clin Res 2011;4(4):5-8.

4. Dansena $\mathrm{H}, \mathrm{Hj} \mathrm{D}$, Chandrakar K. Pharmacological potentials of pyrimidine derivative: A review. Asian J Pharm Clin Res 2015;8(4):171-7.

5. Cinelli MA, Morrell A, Dexheimer TS, Scher ES, Pommier Y, Cushman M. Design, synthesis, and biological evaluation of 14-substituted aromathecins as topoisomerase I inhibitors. J Med Chem 2008;51(15):4609-19.

6. Chen J, Lu MM, Liu B, Chen Z, Li QB, Tao LJ, et al. Cheminform Abstract: A versatile domino process for the synthesis of substituted 3-aminomethylene-chromanones and 2-pyridones catalyzed by CsF. Bioorg Med Chem Lett 2012;22:2300.

7. Nakao Y, Idei H, Kanyiva KS, Hiyama T. Hydrocarbamoylation of unsaturated bonds by nickel/Lewis-acid catalysis. J Am Chem Soc 2009;131(14):5070-1.

8. Tuson J. Encyclopedia of the alkaloids. J Chem Soc 1864;17:195.

9. Maquenne L, Philippe L, Hebd CR. 4-Hydroxy-2-pyridone alkaloids: Structures and synthetic approaches. Acad Sci 1904;139:840.

10. Basyouni SH, El Brewer D, Vining LC. Comparative morphology and biology of the fungi. Can J Bot 1968;46:441.

11. McInnes AG, Smith V, Wat CK, Vining LC, Wright V. Tenellin and bassianin, metabolites of Beauveria species. Structure elucidation with $15 \mathrm{~N}$ - and doubly $13 \mathrm{C}$-enriched compounds using $13 \mathrm{C}$ nuclear magnetic resonance spectroscopy. J Chem Soc Chem Commun 1974;1:281-2.

12. Casinovi CG, Grandolini G, Mercantini R, Oddo N, Olivieri R, Tonolo A. A new antibiotic produced by a strain of Aspergillus flavipes. Tetrahedron Lett 1968;27:3175-8.

13. Ando K, Suzuki S, Saehi T, Tamura G, Arima K. Novel tetramic acids and pyridone alkaloids, militarinones $\mathrm{B}, \mathrm{C}$, and $\mathrm{D}$, from the insect pathogenic fungus Paecilomyces militaris. J Antibiot 1969;22:189-94.

14. Hayakawa S, Minato H, Katagiri K. The ilicicolins, antibiotics from Cylindrocladium ilicicola. J Antibiot (Tokyo) 1971;24(9):653-4.

15. Wolf $\mathrm{H}, \mathrm{Z} €$ ahner $\mathrm{H}$. Protein synthesis elongation factor eftufrom Streptomyces collinus producing kirromycin. Arch Microbiol 1972;83:147-54.

16. Breinhold J, Ludvigsen S, Rassing BR, Rosendahl CN, Nielsen SE, Olsen CE. Oxysporidinone: A novel, antifungal N-methyl-4-hydroxy2-pyridone from Fusarium oxysporum. J Nat Prod 1997;60(1):33-5.

17. Singh SB, Liu W, Li X, Chen T, Shafiee A, Card D, et al. Antifungal spectrum, in vivo efficacy, and structure-activity relationship of ilicicolin h. ACS Med Chem Lett 2012;3(10):814-7. 
18. Storck P, Aubertinb AM, Grierson DS. Studies on compounds consisting quinoline and 2-pyridone heterocycles. Tetrahedron Lett 2005;46:2919.

19. Cocco MT, Congiu C, Onnis V. New bis(pyridyl)methane derivatives from 4-hydroxy-2-pyridones: Synthesis and antitumoral activity. Eur J Med Chem 2003;38(1):37-47.

20. Cocco MT, Congiu C, Onnis V. Synthesis and antitumour activity of 4-hydroxy-2-pyridone derivatives. Eur J Med Chem 2000;35(5):545-52.

21. Lv Z, Sheng C, Wang T, Zhang V, Liu J, Feng V, et al. Pathologically decreased miR-26a antagonizes apoptosis and facilitates carcinogenesis by targeting $\mathrm{MTDH}$ and $\mathrm{EZH} 2$ in breast cancer. J Med Chem 2010;53:660.

22. Wallace EM, Lyssikatos J, Blake JF, Seo J, Yang HW, Yeh TC, et al. Potent and selective mitogen-activated protein kinase kinase (MEK) 1,2 inhibitors 1. 4-(4-bromo-2-fluorophenylamino)-1- methylpyridin2(1H)-ones. J Med Chem 2006;49(2):441-4.

23. Hu E, Tasker A, White RD, Kunz RK, Human J, Chen V, et al. Discovery of aryl aminoquinazoline pyridones as potent, selective, and orally efficacious inhibitors of receptor tyrosine kinase c-Kit. J Med Chem 2008;51(11):3065-8

24. Li R, Xue L, Zhu T, Jiang Q, Cui X, Yan Z, et al. Design and synthesis of 5-aryl-pyridone-carboxamides as inhibitors of anaplastic lymphoma kinase. J Med Chem 2006;49(3):1006-15

25. Lenaerts AJ, Bitting C, Woolhiser L, Gruppo V, Marietta KS, Johnson CM, et al. Evaluation of a 2-pyridone, KRQ-10018, against Mycobacterium tuberculosis in vitro and in vivo. Antimicrob Agents Chemother 2008;52(4):1513-5.

26. Dragovich PS, Prins TJ, Zhou R, Johnson TO, Hua Y, Luu HT, et al. Structure-based design, synthesis, and biological evaluation of irreversible human rhinovirus $3 \mathrm{C}$ protease inhibitors. 8. Pharmacological optimization of orally bioavailable 2-pyridonecontaining peptidemimetics. J Med Chem 2003;46(21):4572-85.

27. Cheney IW, Yan S, Appleby T, Walker H, Vo T, Yao N, et al. Identification and structure-activity relationships of substituted pyridones as inhibitors of Pim-1 kinase. Bioorg Med Chem Lett 2007;17(6):1679-83.

28. Schröder P, Förster T, Kleine S, Becker C, Richters A, Ziegler S, et al. Neuritogenic militarinone-inspired 4-hydroxypyridones target the stress pathway kinase MAP4K4. Angew Chem Int Ed Engl 2015;54(42):12398-403

29. Schmidt K, Günther W, Stoyanova S, Schubert B, Li Z, Hamburger M. Militarinone A, a neurotrophic pyridone alkaloid from Paecilomyces militaris. Org Lett 2002;4(2):197-9.

30. Wagenaar MM, Gibson DM, Clardy J. Akanthomycin, a new antibiotic pyridone from the entomopathogenic fungus Akanthomyces gracilis. Org Lett 2002;4(5):671-3.

31. Isaka M, Tanticharoen M, Kongsaeree P, Thebtaranonth Y. Structures of cordypyridones A-D, antimalarial N-hydroxy- and N-methoxy-2pyridones from the insect pathogenic fungus Cordyceps nipponica. J Org Chem 2001;66(14):4803-8.

32. Jegorov A, Matha V, Husak M, Kratochvil B, Stuchilik J, Sedmera P, et al. Structures of cordypyridones A-D, antimalarial N-hydroxy-and $\mathrm{N}$-methoxy-2-pyridones from the insect pathogenic fungus cordyceps nipponica. J Chem Soc Dalton Trans 1993;1:1287-93.

33. TePaske MR, Gloer JB, Wicklow DT, Dowd PF. Chromatography of mycotoxins: Techniques and applications. Tetrahedron Lett 1991;32:5687.

34. Snider BB, Lu Q. Formal synthesis of 15-acetoxypallescensin-A. Synth Commun 2001;31:2667

35. Henry AA, Yu C, Romesberg FE. Determinants of unnatural nucleobase stability and polymerase recognition. J Am Chem Soc 2003; 125(32):9638.

36. Li L, Degardin M, Lavergne T, Malyshev DA, Dhami K, Ordoukhanian P, et al. Natural-like replication of an unnatural base pair for the expansion of the genetic alphabet and biotechnology applications. J Am Chem Soc 2014;136(3):826-9.

37. Chen Y, Wang F, Jia A, Li X. Encyclopedia of reagents for organic synthesis. Chem Sci 2012;3:3231.

38. Cheng D, Gallagher T. Direct and regioselective C-H alkenylation of tetrahydropyrido[1,2-a]pyrimidines. Org Lett 2009;11(12):2639-41.

39. Ortiz-de-Elguea V, Sotomayor N, Lette E. Palladium-catalyzed direct alkenylation of 4-hydroxy-2-pyridones. Adv Synth Catal 2015;357:463.
40. Nakatani A, Hirano K, Satoh T, Miura V. Nickel-catalyzed direct alkylation of heterocycles with $\alpha$-bromo carbonyl compounds: C3selective functionalization of 2-pyridones. Chem Eur J 2013;19:7691.

41. Modak A, Rana S, Maiti D. Iron-catalyzed regioselective direct arylation at the C-3 position of N-Alkyl-2-pyridone. J Org Chem 2015;80(1):296-303.

42. Nakatani A, Hirano K, Satoh T, Miura M. A concise access to (polyfluoroaryl)allenes by $\mathrm{Cu}$-catalyzed direct coupling with propargyl phosphates. J Org Chem 2014;79:1377.

43. Tamura R, Yamada Y, Nakao Y, Hiyama T. Quinoline-fused heterocycles via rhodium(III)-Catalyzed $\mathrm{C}-\mathrm{C} / \mathrm{C}-\mathrm{N}$ coupling of bifunctional substrates. Chem Int Ed 2012;51:5679.

44. Nakao Y, Idei H, Kanyiva KS, Hiyama T. Direct alkenylation and alkylation of pyridone derivatives by Ni/AlMe3 catalysis. J Am Chem Soc 2009;131:15996

45. Anagnostaki EE, Fotiadou AD, Demertzidou V, Zografos AL. Palladium catalyzed C3-arylation of 4-hydroxy-2-pyridones. Chem Commun (Camb) 2014;50(52):6879-82.

46. Sugandha C, Jigar SD, Aditya A, Preetesh M. JAK/STAT as a novel target for treatment of leukemia. Int J Pharm Pharm Sci 2014;6(1):1-7.

47. Partha GS, Manna K, Udayan B, Manik D, Priyatosh S. Synthetic strategies and pharmacology of 2-Oxo-3-cyanopyridine derivatives: A review. Int J Pharm Pharm Sci 2014;6(4):39-42.

48. Karam C, Suchita P, Rakesh KT, Shirazi AN, Sumit K, Keykavous P, et al. Synthesis and evaluation of c-Src kinase inhibitory activity of pyridin-2(1H)-one derivatives. Bioorg Chem 2014;53:75-82.

49. Mijin DZ, Markovic JM, Brkovic DV, Aleksandar D. Marinkovic microwave-assisted synthesis of 2-pyridone and 2-pyridone-based compounds. Hem Ind 2014;68(1):1-14.

50. Seifi M, Rabori MK, Sheibani H. Highly efficient method for synthesis of N-amino-2-pyridone derivatives in the presence of catalysts such as magnesium oxide $(\mathrm{MgO})$ and bismuth(III) nitrate pentahydrate (Bi(NO3)3·5H2O). Mod Res Catal 2013;2:8-12.

51. Mehrparvar S, Balalaie S, Rabbanizadeh M, Ghabraie E, Rominger F. An efficient tandem approach for the synthesis of functionalized 2-pyridone-3-carboxylic acids using three-component reaction in aqueous media. Mol Divers 2014;18(3):535-43.

52. Al-Abdullah ES. Synthesis and anticancer activity of some novel tetralin6-yl-pyrazoline, 2-thioxopyrimidine, 2-oxopyridine, 2-thioxo-pyridine and 2-iminopyridine derivatives. Molecules 2011;16(4):3410-9.

53. Lv Z, Sheng C, Wang T, Zhang Y, Liu J, Feng J, et al. Design, synthesis, and antihepatitis $\mathrm{B}$ virus activities of novel 2-pyridone derivatives. J Med Chem 2010;53(2):660-8.

54. Tkachova VP, Gorobets NY, Tkachov RP, Dyachenko OD, Rusanov EB, Dyachenko VD. Reactions of diethyl 2-(ethoxymethylene)malonate with 2-cyanoacetanilides: Unexpected transfer of the ethoxymethylene moiety. ARKIVOC 2010;XI:254-64.

55. Jacinto DA, Valente VM, Barbosa LC, Rathi AH, Donohoe TJ, Thompson AL. Synthesis and phytotoxic activity of new pyridones derived from 4-hydroxy-6-methylpyridin-2(1H)-one. Molecules 2009; $14: 4973-86$.

56. Tugusheva NZ, Alekseeva LM, Shashkov V, Chernyshev V, Granika V. Synthesis and functionalization of 4 arylamino2-pyridone derivatives. Russ Chem Bull Int Ed 2006;55(8):1475-86.

57. Yu N, Behrooz G, Belaj F. Carbon bond formation via rhodium (III)catalyzed oxidative C-H activation. Tetrahedron 2006;60:8633-44

58. Ando M, Wada T, Sato N. Facile one-pot synthesis of N-difluoromethyl2-pyridone derivatives. Org Lett 2006;8:3805-8.

59. Kajal C, Devakumar C. Quantitative structure-activity relationship analysis as a tool to evaluate the mode of action of chemical hybridizing agents for wheat (Triticum aestivum L.) J Agric Food Chem 2005;53:3468-75.

60. Desai NC, Shihory NR, Kotadiya GM. Facile synthesis of benzimidazole bearing 2-pyridone derivatives as potential antimicrobial agents. Chin Chem Lett 2014;25(2):305-7.

61. Fischer CB, Polborn K, Steininger H, Zipse H. Synthesis and solid-state structures of alkyl-substituted 3-cyano-2-pyridones. Z Naturforsch 2004;59:1121-31. 